\title{
Conselho de Classe On-Line: Uma prática coletiva com professores do Ensino Fundamental
}

Michélle Barreto Justus

Mary Ângela Teixeira Brandalise

\section{Resumo}

O presente artigo apresenta a análise de uma prática de Conselho de Classe realizada no interior de uma escola pública estadual paranaense de Ensino Fundamental, com apoio do software Conselho de Classe on-line, o qual permite a visualização de elementos relacionados à avaliação da aprendizagem dos estudantes. Tem por objetivo apresentar a avaliação realizada pelos professores usuários do software para a prática avaliativa na reunião do Conselho de Classe. A pesquisa de abordagem qualitativa adotou a análise documental e o questionário enviado pela plataforma google forms para 10 professores da escola pesquisada. Os resultados mostram que o software se mostrou eficiente no levantamento e registro das avaliações dos alunos e, ao mesmo tempo oportunizou uma experiência avaliativa positiva aos professores das escolas. As contribuições por eles declaradas referem-se à: reavaliação dos alunos e das avaliações realizadas, assim como à análise de resultados para atender ou corrigir o atendimento individual aos alunos com dificuldades; reflexão coletiva sobre a condução do processo de avaliação da aprendizagem pelo professor; análise dos resultados dos alunos propiciada pelos relatórios do software tanto para professores como para a equipe escolar; e definição de ações no interior da escola com base nas informações organizadas no software. Desburocratizar a realização os conselhos de classe nas escolas pode ser um dos caminhos para criar espaços de avaliação coletiva em uma perspectiva formativa. Acredita-se que o software Conselho de Classe On-line pode contribuir nessa direção.

Palavras-chave: Conselho de Classe On-line. Avaliação da Aprendizagem. Prática Avaliativa. 


\title{
On-Line Class Council: A collective practice with Fundamental Education Teachers
}

\author{
Michélle Barreto Justus \\ Mary Ângela Teixeira Brandalise
}

\section{Abstract}

This paper presents the analysis of a Class Council practice carried out within a state public school in Paraná, supported by the online Class Council software, which allows the visualization of elements related to the learning assessment of the students. It aims to present the assessment made by teachers using the software for evaluative practice at the Class Council meeting. The qualitative approach research adopted the document analysis and the questionnaire sent by the google forms platform to 10 teachers of the researched school. The results show that the software proved to be efficient in surveying and recording student evaluations and at the same time provided a positive evaluative experience for school teachers. The contributions declared by them refer to: reassessment of students and evaluations performed, as well as analysis of results to meet or correct individual assistance to students with difficulties; collective reflection on the conduct of the learning assessment process by the teacher; student outcome analysis provided by software reports for both teachers and school staff; and definition of actions within the school based on information organized in the software. Reducing bureaucracy in conducting class councils in schools can be one of the ways to create spaces for collective assessment in a formative perspective. It is believed that Online Class Council software can contribute in this direction.

Keywords: Online Class Council. Learning Assessment. Evaluative Practice. 


\section{Introdução}

A questão da avaliação no interior das escolas é um campo repleto de contradições em seus aspectos teóricos e práticos. Muitas vezes, a avaliação da aprendizagem, revelada por meio de práticas avaliativas nas quais prevalecem concepções da avaliação como um mero instrumento de medir, quantificar, comparar e classificar a capacidade discente em armazenar informações, descoladas da realidade, refletem uma concepção simplista que reduz a aprendizagem à expectativa de um comportamento esperado ou à demonstração de respostas corretas mediante um momento de exame.

Diante da frequência de práticas avaliativas voltadas somente para resultados e não como um processo, é necessário discutir sobre as concepções de avaliação que permeiam as práticas docentes, em seus diversos momentos do ano letivo e em suas diferentes modalidades.

Um desses momentos avaliativos - o Conselho de Classe - é parte integrante da rotina pedagógica da escola, o qual tem por finalidade servir de momento para refletir sobre a caminhada construída durante um determinado período dos processos de ensino e aprendizagem, normalmente sendo organizado pela equipe pedagógica e professores das turmas da escola.

Em linhas gerais, um Conselho de Classe se organiza em três 3 momentos distintos: o pré-conselho que consiste no levantamento de dados sobre o desempenho discente; o conselho de classe em si que é a reunião do corpo docente e equipe pedagógica para análise do desempenho discente e proposição de ações pedagógicas; e o pós-conselho que se refere a implementação das ações definidas coletivamente na fase anterior. A forma como são obtidas e registradas as informações sobre os alunos nas diferentes etapas do Conselho de Classe pode variar de escola para escola, pois ela precisa se adaptar à realidade e à necessidade do ambiente escolar no qual estão inseridas.

Os procedimentos para a coleta de dados acerca da aprendizagem dos alunos podem ocorrer em encontros individuais do pedagogo responsável pela turma com professores em suas horas-atividade, ou através de registros em documentos próprios, visto que esse processo avaliativo e de registro dependem, de certa maneira, da condução feita pelo atores escolares (pedagogos, professores, gestores).

Neste artigo apresentamos a análise de uma prática de Conselho de Classe realizada no interior de uma escola pública estadual paranaense de Ensino Fundamental com apoio do software Conselho de Classe on-line, o qual permite a visualização de elementos relacionados à avaliação da aprendizagem dos estudantes. A proposição do uso desse auxílio tecnológico teve o intuito de dinamizar o processo avaliativo no Conselho de Classe, para professores do Ensino Fundamental, numa perspectiva de facilitação de registro da avaliação dos alunos, tornando o processo de interpretação e análise dos resultados mais ágil e interativo, e talvez, mais eficiente no que diz respeito à superação das dificuldades que se apresentam no momento 
de levantamento e organização dos dados da aprendizagem dos alunos para a realização do Conselho de Classe.

O texto deste artigo está organizado em 3 seções, além desta introdução e das considerações finais. Na primeira, buscou-se situar a temática no que se refere a origem do Conselho de Classe e sua realização no interior das escolas, bem como a contextualização do mesmo na realidade paranaense. Na segunda parte, foram abordados alguns aspectos e conceitos da avaliação da aprendizagem e a sua relação com as práticas pedagógicas, dentre elas as práticas avaliativas; e na terceira, são apresentados os dados sobre a avaliação realizada pelos professores usuários do software, tomando por base quesitos como uso, facilidade e contribuição do sistema para sua participação durante realização do Conselho de Classe na escola.

\section{Conselho de Classe: aspectos históricos e conceituais}

Para compreender o processo avaliativo relativo ao Conselho de Classe, inicialmente é necessário conhecer a sua origem. Historicamente, a "ideia" de Conselho de Classe se deu numa experiência francesa, por volta do ano de 1945, baseada na necessidade de realização de trabalhos interdisciplinares com classes de experimentação naquele contexto.

No entanto, só em 1959, em virtude da reforma francesa de ensino é que os conselhos se estabeleceram como prática em seus diferentes formatos: o Conselho de Classe (na esfera da turma); o Conselho de Orientação (no âmbito do estabelecimento); e de modo mais amplo, o Conselho Departamental de Orientação. Almejava-se com esta reforma "organizar um sistema escolar fundado na observação sistemática e contínua dos alunos, com vistas a oferecer, a cada um, o ensino que corresponda a seus gostos e aptidões" (DALBEN, 2004, p. 22).

A experiência francesa foi vivenciada em Sèvres, no ano de 1958, por dez educadores brasileiros estagiários, que trouxeram a ideia de "conselho" ao Brasil, sendo o Rio de Janeiro o estado pioneiro nesta prática educativa.

Desde a implantação do Conselho de Classe nas escolas, previa-se para ele "uma função de cunho essencialmente pedagógico, objetivando, principalmente, auxiliar o processo avaliativo, e partia-se da necessidade de maior conhecimento do aluno e do pressuposto de que o processo coletivo de avaliação é qualitativamente superior ao individual”. (DALBEN, 2004, p. 35). A autora explica que os Conselhos de Classe teriam "[...] o papel de aglutinar as diferentes análises e avaliações dos diversos profissionais, permitindo análises globais do aluno em relação aos trabalhos desenvolvidos e a estruturação de trabalhos pedagógicos segundo opções coletivas" (DALBEN 2004, p. 35).

No Brasil, a institucionalização do Conselho de Classe se deu no bojo de reformas decorrentes do Acordo MEC-USAID, na década de 1960, especialmente relacionada ao 
Programa de Expansão e Melhoria do Ensino (PREMEN - regulamentado pelo decreto $\mathrm{n}^{\mathrm{o}}$ 63.914/68) e na lei $\mathrm{n}^{0} 5692 / 71$, fundamentando e organizando os regimentos escolares das escolas brasileiras.

Por meio de orientações advindas desses documentos normativos, os Conselhos Estaduais de Educação produziam pareceres e resoluções que encaminhavam e oficializavam, de certo modo, a avaliação coletiva na escola (num modelo semelhante ao conselho de classe atual), mas ainda sim sem deixar claro como se daria a execução dessa proposta avaliativa coletiva (DALBEN, 2004, p. 26).

Com o avanço temporal e as transformações ocorridas em decorrência das mudanças nos contextos político e social a partir dos anos da década de 1980, o Conselho de Classe também foi ganhando outros contornos. As políticas implementadas a partir de então acabaram por oficializar alguns elementos no interior da escola, tais como o Conselho Escolar, o Projeto Político-Pedagógico e a o próprio Conselho de Classe.

A história de implementação dos Conselhos de Classe demonstra que esse órgão adquiriu formatos diferentes, estilos de orientação pedagógica diferentes, composições e periodicidade de realização também variadas a partir dos objetivos e metas delineadas pelos projetos pedagógicos das escolas e pelos membros que o coordenam. (DALBEN, 2010, p. 1).

No caso da rede pública estadual paranaense, atualmente, o Conselho de Classe compõe uma das instâncias colegiadas, juntamente com outras, como a APMF (Associação de pais, alunos e funcionários), o Conselho Escolar e o Grêmio Estudantil. Essas organizações são constituídas por representantes de todos os segmentos da comunidade escolar e tem por objetivo auxiliar o diretor na função de Gestor Escolar, assim como nas decisões e encaminhamentos para solução de problemas do cotidiano da escola. Visa a melhoria da qualidade dos processos de ensino e aprendizagem (PARANÁ, 2019).

Os princípios da participação, da transparência e da implementação de políticas educacionais comprometidas com a qualidade do ensino fazem parte do que é entendido por “Gestão Democrática”. No intuito de introduzir nas instituições escolares princípios da gestão democrática, as instâncias colegiadas ganharam força e espaço, e em 2007, na gestão do governador Roberto Requião, foi enviado às escolas um "Caderno de Apoio para Elaboração do Regimento Escolar”, elaborado pela SEED/PR (Secretaria de Estado de Educação do Paraná), documento que apresentava o Conselho de Classe como uma das instâncias colegiadas de gestão do trabalho pedagógico.

Conforme as orientações do documento, o Conselho de Classe deveria integrar o projeto político pedagógico da escola e em seu regimento definia-se que ele deveria ser 
presidido pelo(s) diretor(res) com participação da equipe pedagógica, dos docentes e alunos que atuassem numa mesma turma e/ou série. Desenvolver-se-ia em dois momentos: um préconselho realizado com a participação de toda a classe e sob a coordenação do pedagogo ou professor representante de turma, e o conselho de classe integrado, com a participação de diretores, pedagogos, professores e, facultativamente, alunos e pais por turma e/ou série (PARANÁ, 2007).

A instrução ${ }^{0}$ 15/2017 da Superintendência da Educação, da SEED/PR explicita que o:

Conselho de Classe constitui-se parte integrante do processo avaliativo, onde todos os sujeitos, de forma coletiva, se posicionam frente ao diagnóstico, analisam e discutem acerca dos dados, avanços, problemas e proposições, para a tomada de decisões que contemplem encaminhamentos relacionados às metodologias, ações e estratégias que visem à aprendizagem e que levem em conta as necessidades/dificuldades dos(as) estudantes. (PARANÁ, 2017, p. 7 ).

Ainda segundo a instrução, as deliberações do Conselho de Classe podem implicar em ações que dizem respeito:

a) à Equipe Pedagógica, como orientação aos estudantes, orientação ou retorno aos pais ou responsáveis, subsídios aos planejamentos dos docentes, entre outras; b) aos Docentes, como a retomada do Plano de Trabalho Docente (conteúdos, encaminhamentos metodológicos, recursos, critérios e instrumentos de avaliação), na gestão da sala de aula, em encaminhamentos para situações específicas ou individuais; c) à Equipe Diretiva, dando suporte para as decisões tomadas pelo colegiado. (PARANÁ, 2017, p. 7).

Portanto, o Conselho de Classe se constituiu como órgão colegiado, de natureza consultiva e deliberativa, $\mathrm{e}$

[...] está presente na organização da escola, em que os vários professores das diversas disciplinas, juntamente com os coordenadores pedagógicos, ou mesmo os supervisores e orientadores educacionais, reúnem-se para refletir e avaliar o desempenho pedagógico dos alunos das diversas turmas, séries ou ciclos. (DALBEN, 2004, p. 31).

O Conselho de Classe prevê algumas características básicas que o tornam diferente dos demais momentos avaliativos, e lhe dão tamanha importância, considerando: a) a forma de participação dos atores pedagógicos; b) a sua organização interdisciplinar; e c) a centralidade na avaliação escolar.

Nas palavras de Dalben (2004, p. 32), a forma de participação no Conselho de Classe, que se constitui com a participação direta de todos os professores que participam do processo pedagógico faz com que estes possam refletir sobre sua prática docente, mesmo que indiretamente, quando tem um momento para analisar e discutir o processo de trabalho desenvolvido em sala de aula. 
Nesse momento coletivo, se estabelece uma rede de relações, visto que um professor pode, por exemplo, participar de diversas reuniões de Conselho de Classe, abordando situações e avaliações de diferentes turmas, turnos e grupos de professores. Desse modo, cria-se uma atmosfera de inter-relação, de participação efetiva e entrelaçada, permitindo um processo de análise, reflexão e discussão coletiva em torno da dinâmica escolar (DALBEN, 2004).

As outras características citadas por Dalben (2004) referem-se à organização interdisciplinar e à avaliação escolar, nas quais o estudo das situações e a tomada de decisões reafirmam o caráter deliberativo do Conselho de Classe. É possível, por exemplo, definir ou realinhar os objetivos de ensino, as metodologias e estratégias de ensino, os critérios de seleção de conteúdo, os projetos coletivos de ensino, as formas, critérios e instrumentos de avaliação, as formas de acompanhamento pedagógico, os critérios para análise de desempenho dos alunos, as formas de registro para informação do desempenho dos alunos aos seus pais, as propostas curriculares adaptadas ou, ainda, a proposição de estudos complementares (DALBEN, 2004).

\section{Avaliação da/para a aprendizagem e as práticas pedagógicas}

Sendo a avaliação um campo vasto de definições e concepções próprias relacionadas a um determinado contexto histórico e social, vale lembrar que não conseguiremos esgotar o assunto neste artigo. Assim, é mister retomar alguns aspectos sobre a relação entre as práticas pedagógicas e as práticas avaliativas, bem como conceitos relacionados a avaliação da aprendizagem em suas modalidades somativa e formativa, ou dito de outro modo, sobre a avaliação da e para a aprendizagem.

Segundo Franco (2016, p.18) "as práticas pedagógicas devem se estruturar como instâncias críticas das práticas educativas, na perspectiva de transformação coletiva dos sentidos e significados das aprendizagem”, daí depreende-se que há no trabalho docente uma íntima relação entre as práticas pedagógicas e as práticas avaliativas pois elas se relacionam e se influenciam mutuamente. "Quando se fala em prática pedagógica, refere-se a algo além da prática didática, envolvendo: as circunstâncias da formação, os espaços-tempos escolares, as opções da organização do trabalho docente, as parcerias e expectativas do docente" (FRANCO, 2016, p.18).

As práticas pedagógicas dos professores só têm sentido se estiverem ligadas às práticas avaliativas, pois são estas que possibilitam reavaliar o caminho traçado e podem apontar o que pode ser aperfeiçoado para a aprendizagem efetiva dos alunos. De modo análogo, as práticas avaliativas refletem as concepções de avaliação que fundamentam as práticas pedagógicas, numa relação intrínseca e cíclica.

Perrenoud (2008, p. 68) destaca a importância de se ter clareza sobre o que se pretende com a avaliação, afirmando que "uma avaliação formativa (...) dá informações, 
identifica erros, sugere interpretações quanto às estratégias e atitudes dos alunos e, portanto, alimenta diretamente a ação pedagógica”.

Por outro lado, na maioria das escolas brasileiras, o Conselho de Classe, embora tenha sua importância reconhecida, ainda não conseguiu se consolidar como uma prática pedagógica desvinculada da ideia de medir, classificar ou categorizar, e nem se desvencilhar da concepção de avaliação somente como um produto, como um "resultado", aquele que se dá ao final do processo educativo.

Além disso, a concepção de avaliação da aprendizagem no momento do Conselho de Classe varia e depende da formação profissional e experiência pessoal de cada professor, da proposta de avaliação da escola e do sistema educativo ao qual pertence, dos pressupostos filosóficos, epistemológicos e metodológicos do Projeto Político Pedagógico que orienta as ações educativas da escola.

Muitas vezes os professores até chegam ao consenso de que a avaliação precisa ser encarada como um processo (avaliação formativa). No entanto, suas práticas demonstram que há um abismo entre o que se reconhece como importante e o que é feito na concretude da sala de aula. De acordo com Taras (2005), apesar de a maioria dos professores reconhecer a importância da avaliação formativa, o contexto avaliativo rotineiro nas escolas ainda se apresenta num viés mais somativo, ou seja, o corpo docente aceita conceitualmente a avaliação formativa, mas pouco a prática.

Hadji (2001, p. 20) afirma que "é a intenção dominante do avaliador que torna a avaliação formativa”. Para que a avaliação da aprendizagem atenda as funções formativas e somativas faz-se necessário que a intenção seja contemplada no planejamento docente, indicando quais ações serão realizadas para que os dados coletados com finalidades somativas ajudem o aluno na sua aprendizagem e que os originários dos propósitos formativos conduzam a um processo de ação-reflexão-ação que possibilite validar a qualidade da avaliação somativa.

A avaliação formativa segundo Fernandes (2009) está mais associada ao desenvolvimento, à regulação e à autorregulação dos processos de ensino e aprendizagem, e a avaliação somativa informa o que foi aprendido pelos alunos com o objetivo de apresentar os resultados alcançados publicamente, estando mais associada à prestação de contas e a certificação.

As modalidades de avaliação formativa e somativa são fundamentais para o entendimento do sentido pedagógico da avaliação escolar, pois ambas têm uma função de regulação. Na avaliação formativa ela está voltada aos processos de ensino e aprendizagem, a adequação da formação dos alunos, indo além da verificação de conhecimento; na avaliação somativa a função de regulação está voltada ao atendimento das exigências do sistema de ensino. 
Nessa perspectiva, é possível estabelecer relação entre o processo avaliativo de caráter formativo e a forma como se "faz" a avaliação $d a$ aprendizagem e para a aprendizagem. Autores como Lopes e Silva (2012), Fernandes (2019) contribuem no esclarecimento da diferenciação dessas duas funções de avaliação de aprendizagem.

A avaliação formativa está inexoravelmente associada à distribuição de feedback de elevada qualidade, é de natureza contínua e tem como fundamental propósito ajudar os alunos a aprender. Por este motivo, passou a ser designada como Avaliação para as Aprendizagens. A avaliação sumativa, ao contrário do que aconteceu durante décadas, não está mais exclusivamente associada à atribuição de classificações. Na verdade, a construção teórica permitiu que ela pudesse ter uma utilização formativa e nessas circunstâncias, pudesse estar igualmente ao serviço das aprendizagens. [...] Hoje, a avaliação sumativa é designada como Avaliação das Aprendizagens. (FERNANDES, 2019, p.157).

A avaliação $d a$ aprendizagem vincula-se a uma concepção somativa de avaliação com o intuito de descrever o desempenho do aluno, verificando se ele aprendeu ou não, ocorrendo geralmente ao final de uma unidade de ensino. Essa concepção de avaliação $d a$ aprendizagem tem como centro o professor, para averiguar o nível de desenvolvimento da aprendizagem do aluno, determinando seu sucesso ou fracasso.

A avaliação para a aprendizagem relaciona-se a uma concepção formativa de avaliação, visto que acompanha o processo de aprendizagem dos alunos, de forma contínua. Nessa perspectiva, os atores escolares (professores e alunos) constituem-se como agentes cooperativos de modo a participar ativa e intencionalmente nos processos avaliativos (SILVA e SILVA, 2019, no prelo).

A avaliação para a aprendizagem possui um caráter formativo, cujo objetivo é investigar, acompanhar e apoiar o desenvolvimento do aluno para que sua aprendizagem tenha um significado para a vida; já a avaliação $d a$ aprendizagem apresenta um caráter somativo, com o intuito de certificar as aprendizagens, ao final de determinado período do processo de ensino e aprendizagem.

Por fim, é importante ressaltar que essas diferentes concepções de avaliação formativa e somativa, da e para a aprendizagem - são importantes e complementares nos processos pedagógicos e avaliativos. Cada perspectiva tem a sua contribuição, dependendo do contexto e dos objetivos que são considerados no processo de avaliação educacional e o Conselho de Classe, cujo foco central é a avaliação escolar, é a instância coletiva por excelência de reflexão e discussão da/para avaliação da aprendizagem.

\section{O software Conselho de Classe On-line: funcionalidades e utilização na escola}

O software colaborativo Conselho de Classe on-line foi uma proposta "que envolveu diferentes profissionais da rede estadual, desde sua programação até a utilização por 
professores e pedagogos, num esforço coletivo de organizar e dinamizar uma das instâncias de maior importância pedagógica das escolas públicas brasileiras, o conselho de classe" (BONFIM, 2014, p. 3). O programa foi criado com o propósito de que a equipe pedagógica e os docentes da escola pudessem organizar as informações da avaliação da aprendizagem dos alunos a fim de levar dados sistematizados para reflexão e discussão coletiva no momento da reunião do Conselho de Classe.

As funcionalidades7 do Programa são: a) cadastrar turmas no sistema; b) cadastrar estudantes no sistema; c) cadastrar/remover professores no sistema; e) movimentar alunos nas turmas; f) adicionar/remover fotos dos alunos; g) editar as turmas/alunos no sistema; $\mathrm{h}$ ) alterar senhas de logins cadastrados; i) abrir, fechar bimestre; j) mudar o bimestre ativo; k) mudar o ano ativo; l) definir relação Professor - Disciplina - Turmas; m) acessar diversos relatórios de turmas avaliadas; $n$ ) verificar os dados inseridos pelos professores; o) verificar dados de qualquer ano; p) acessar diversos relatórios de turmas avaliadas.

Considerando a necessidade de experimentação do software Conselho de Classe online para verificar a viabilidade de uso no contexto escolar e a necessidade de alguma modificação ou ajustes nas funcionalidades do programa, ele foi utilizado em caráter experimental numa escola da rede pública estadual do município de Ponta Grossa, sob a coordenação da pedagoga da instituição.

Nessa avaliação participaram 101 alunos, de 4 turmas do período matutino, do $6^{\circ}$ ao $9^{\circ}$ ano do Ensino Fundamental, e 10 professores das disciplinas que compõem a matriz curricular dos anos mencionados para a análise da aprendizagem dos estudantes referente ao $2^{\mathrm{O}}$ bimestre letivo (maio, junho e julho).

O software pode proporcionar uma avaliação do desenvolvimento dos alunos evidenciado o que foi aprendido e as dificuldades de aprendizagem (leitura, escrita, interpretação e raciocínio). Também possibilita avaliar o comportamento dos alunos em sala de aula (conversa e bagunça) e a participação deles nas aulas (muito participativo, média participação ou sem participação), favorecendo o olhar mais detalhado, atento e crítico sobre o desenvolvimento do aluno em sua totalidade, como pode ser observado nos registros contidos no Quadro 1.

7 O tutorial para utilização do software pode ser acessado em: http://www.diaadiaeducacao.pr.gov.br/portals/cadernospde/pdebusca/producoes_pde/2014/2014_u nicentro_ped_pdp_jose_gilberto_nunes_bonfim.pdf 
Quadro 1 - Layout da tela para avaliação do professor

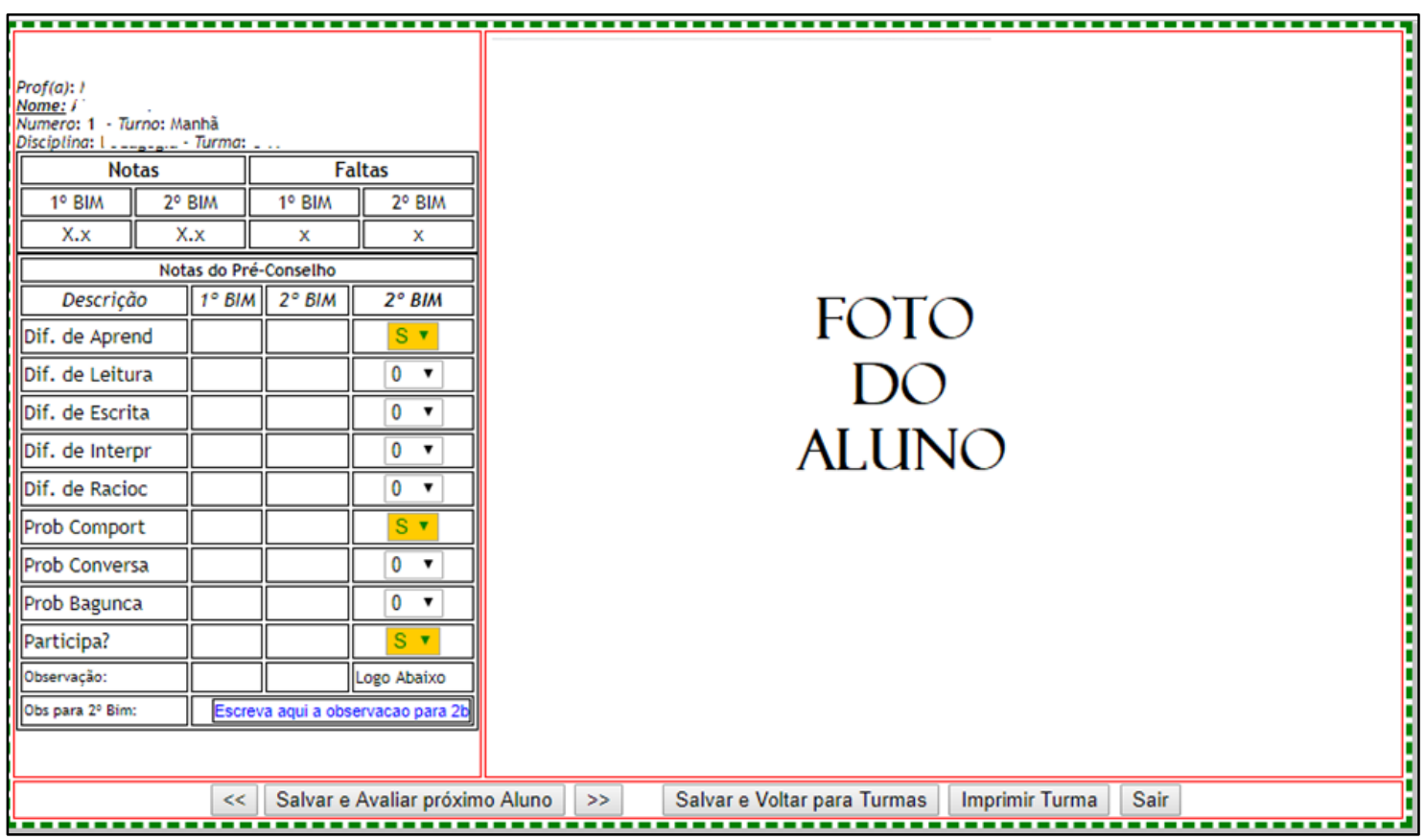

Fonte: As autoras, a partir dos relatórios do software Conselho de Classe on-line (2019).

Os dados iniciais dos alunos, professores e turmas foram cadastrados pela pedagoga, coordenadora da utilização do programa na escola, e contou com o suporte técnico de um servidor da área da tecnologia.

Anteriormente ao manuseio do Conselho de classe on-line, foi proporcionado aos professores uma reunião para conhecimento das funcionalidades do software, na qual eles puderam manuseá-lo e tirar dúvidas que porventura surgissem. Após essa reunião explicativa, o preenchimento das informações relacionadas aos alunos foi disponibilizado aos professores pelo período de um mês, durante o $2^{\mathrm{O}}$ bimestre do ano de 2018.

O software permite aos professores avaliarem as dificuldades de aprendizagem de cada aluno em relação a quesitos como leitura, escrita, interpretação e raciocínio, comportamento e participação do aluno. Caso o professor marque a opção de que o aluno tem dificuldade de aprendizagem, 4 novas abas ficam disponíveis para a marcação do "grau" de dificuldade em relação à leitura, à escrita, à interpretação e ao raciocínio, numa escala de o a 10 (quanto maior a dificuldade, maior o número selecionado).

O professor pode também realizar a avaliação do comportamento, considerando que este fator interfere diretamente na aprendizagem. Caso marque que o aluno não tem dificuldades de comportamento, pode marcar "N" (não tem problemas), e as demais abas também não abrem. 
Por fim, o professor pode ainda avaliar se o aluno participa de suas aulas ( $\mathrm{S}-\mathrm{sim}$; $\mathrm{M}$ - mais ou menos; $\mathrm{N}$ - não), além de ter a opção de utilizar o espaço de observações para registrar comentários específicos sobre a aprendizagem do aluno.

Após o registro dos professores, a pedagoga pode acessar os resultados obtidos como mostra o quadro 2, e elaborar o instrumento formal de registros do Conselho de Classe.

Quadro 2 - Layout da tela após a avaliação ter sido preenchida pelos professores

\begin{tabular}{|c|c|c|c|c|c|c|c|c|c|c|c|}
\hline \multicolumn{12}{|l|}{$1 \cdot \mathrm{A}$} \\
\hline Prof & Motério & D.aprend & D. leitura & D.escrita & D.interpr & D.rocio & P.comport & Piconverso & Pibogunco & participa & $O B S$ \\
\hline & Arte & 5 & 0 & 0 & 0 & 0 & $\mathrm{~N}$ & 0 & 0 & 5 & \\
\hline & Educaçào Física & $\mathrm{N}$ & 0 & 0 & 0 & 0 & $\mathrm{~N}$ & 0 & 0 & $\mathrm{~N}$ & \\
\hline & Geografia & 5 & 0 & 0 & 0 & 0 & $\mathrm{~N}$ & 0 & 0 & 5 & \\
\hline & Língua Portuguesa & $\mathrm{N}$ & 0 & 0 & 0 & 0 & $\mathrm{~N}$ & 0 & 0 & & \\
\hline & Matemática & $s$ & 0 & 0 & 0 & 0 & 5 & 8 & 0 & 5 & Boa aluna \\
\hline
\end{tabular}

Fonte: As autoras, a partir dos relatórios do software Conselho de Classe on-line (2019).

O software ainda possibilita a exploração e utilização de outros dados específicos como, por exemplo, ter uma tabela dos alunos com dificuldades de aprendizagem e/ou comportamento, assim como obter o percentual de alunos da turma com determinada dificuldade, como mostram os quadros 3 e 4.

Quadro 3 - Tela com os resultados da avaliação (Relatório de dificuldade de aprendizagem, problema de comportamento e percentual de cada dificuldade)

\begin{tabular}{|c|c|c|c|c|}
\hline \multicolumn{5}{|c|}{$6^{2} \mathrm{~A}-$ Relatório: Dificuldade de Aprendizagem } \\
\hline $\mathrm{N}^{\circ}$ & Aluno(a) & $1^{\circ} \mathrm{BIM}$ & $2^{\circ} \mathrm{BIM}$ & $3^{\circ} \mathrm{BIM}$ \\
\hline 1 & A & Excelente & Moderada & Excelente \\
\hline$\underline{2}$ & B & Excelente & Gave & Excelente \\
\hline$\underline{3}$ & c & Excelente & Leve & Excelente \\
\hline$\underline{4}$ & D & Excelente & Moderada & Excelente \\
\hline$\underline{5}$ & $\mathrm{E}$ & Excelente & Leve & Excelente \\
\hline \multicolumn{5}{|c|}{$6^{2} \mathrm{~A}$-Relatório: Problema de Comportamento } \\
\hline $\mathrm{N}^{0}$ & Aluno(a) & 1'BIM & $2^{\circ} \mathrm{BIM}$ & 30BIM \\
\hline$\underline{1}$ & A & Excelente & Leve & Excelente \\
\hline$\underline{\underline{2}}$ & B & Excelente & Grave & Excelente \\
\hline$\underline{\underline{3}}$ & $\mathrm{c}$ & Excelente & Leve & Excelente \\
\hline 4 & D & Excelente & Moderada & Excelente \\
\hline$\underline{5}$ & $\mathrm{E}$ & Excelente & Grave & Excelente \\
\hline
\end{tabular}

Fonte: As autoras, a partir dos relatórios do software Conselho de Classe on-line (2019). 
Quadro 4 -Relatório Síntese da Avaliação Final de uma Turma da Escola

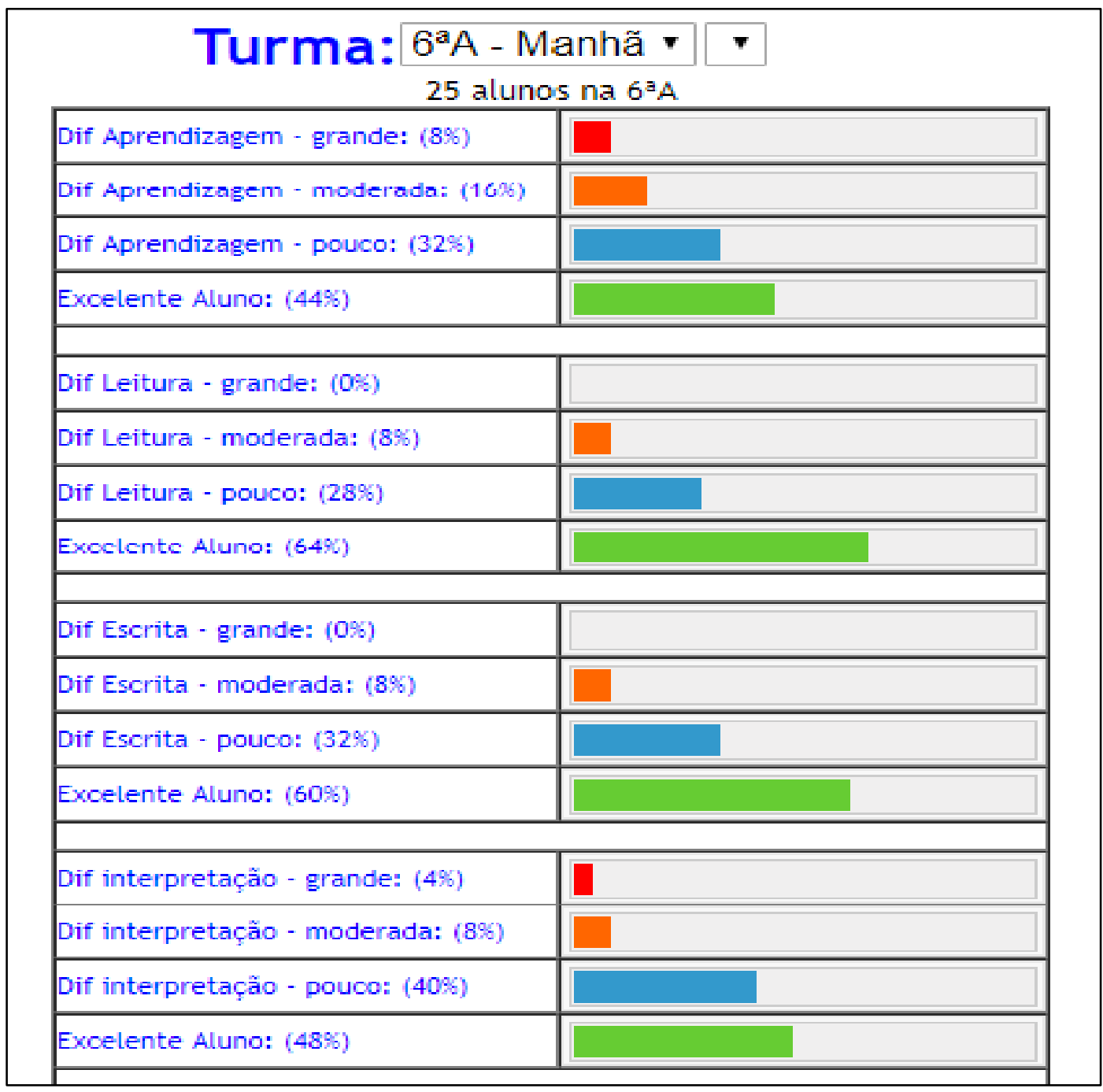

Fonte: As autoras, a partir dos relatórios do software Conselho de Classe on-line (2019).

Os dados referentes à cada turma podem ser organizados antecipadamente em documento próprio do Conselho de Classe e compartilhados em momento oportuno. Os professores têm acesso à todas essas informações. Quando se realiza o Conselho de Classe propriamente dito as observações individuais dos alunos já foram registradas e a discussão coletiva sobre o desenvolvimento dos alunos pode ser realizada com base nos dados registrados no programa e os encaminhamentos de ações podem ser deliberados.

\section{Resultados e discussão}

Após o uso experimental do software durante todo o $2^{\circ}$ bimestre do ano letivo de 2018, os professores foram convidados a responder 6 (seis) questões sobre a utilização do mesmo na escola. As perguntas e opções de respostas estão apresentadas no quadro 5. 
Quadro 5 - Questões para avaliação do uso do software "Conselho de Classe on-line"

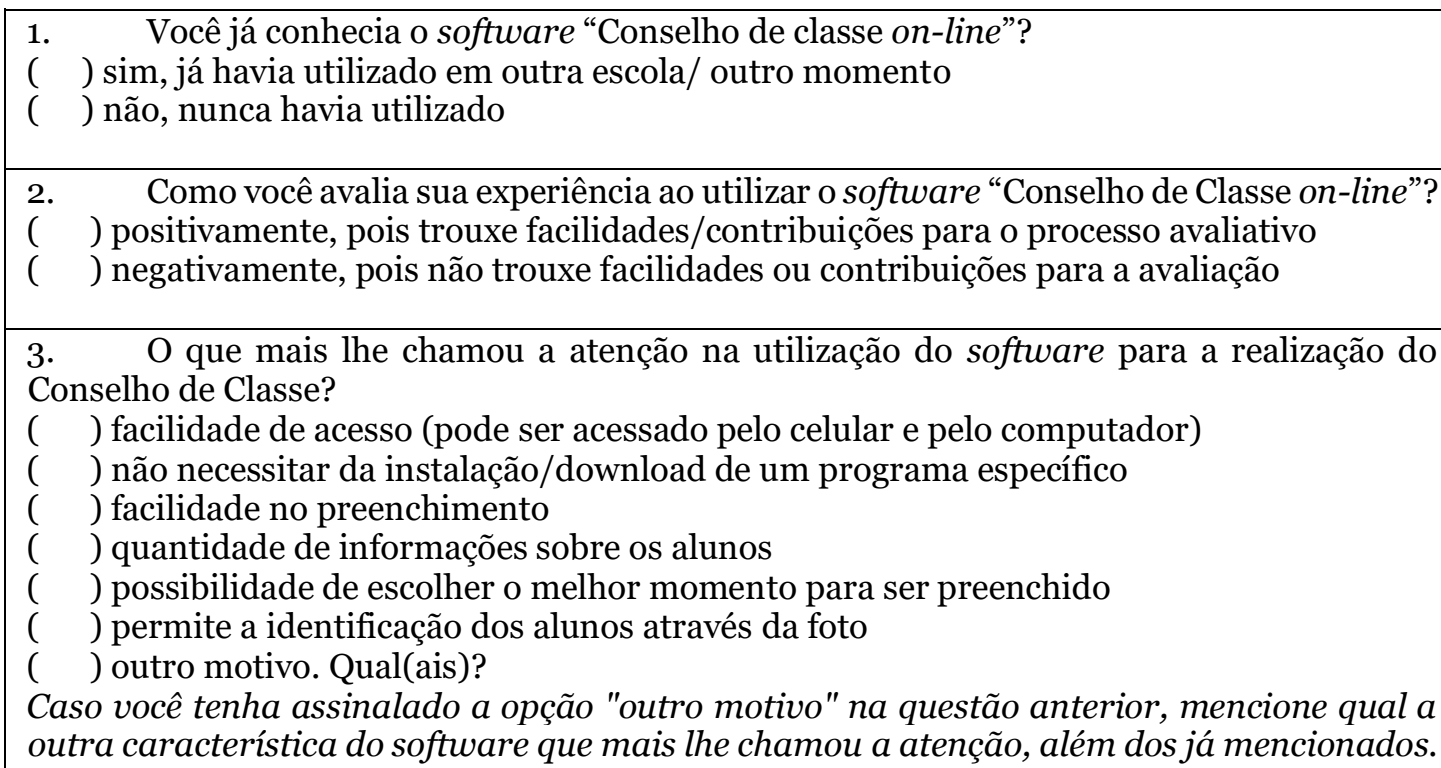

4. Em que momento da avaliação discente você acredita que este software pode ser melhor utilizado?

( ) no Pré-conselho, oferecendo dados prévios à Equipe Pedagógica

( ) no Conselho de Classe em si, revelando dados comuns de alunos para conhecimento de todos os professores.

( ) no Pós-conselho, sugerindo ações pedagógicas específicas, tendo em vista os resultados comuns obtidos.

( ) em todos os momentos anteriormente citados.

5. $\quad$ Em relação ao uso do software (manuseio) ou a utilização posterior dos dados revelados por ele, houve algum ponto que você considera que precisa ser revisto ou aperfeiçoado? Descreva.

6. Em que medida a utilização desse software contribuiu para sua prática pedagógica avaliativa?

Fonte: As autoras (2019).

As questões foram respondidas por professores de todas as disciplinas do Ensino Fundamental, totalizando 10 respondentes.

Os resultados revelaram que 70\% dos professores ainda não conheciam esse recurso tecnológico e 100\% dos respondentes consideraram positiva a experiência com o software para o registro e avaliação da aprendizagem dos alunos.

Quando questionados sobre o que mais chamou a atenção no uso do software, as respostas apontaram que os docentes consideraram importante a facilidade e a agilidade no preenchimento (80\% deles) e a possibilidade de escolher qual o melhor momento para preencher a avaliação (70\%). Sobre os pontos "possibilidade de identificação dos alunos pela foto", "facilidade do acesso" e "quantidade de informações dos alunos”, 50\% dos docentes consideraram as funcionalidades relevantes para o registro das avaliações, seguidos de $30 \%$ 
deles que declararam “não necessitar de instalação de um programa específico" para utilização das avaliações, conforme dados apresentados no gráfico 1.

Gráfico 1 - Aspectos do software Conselho de Classe on-line avaliados pelos professores

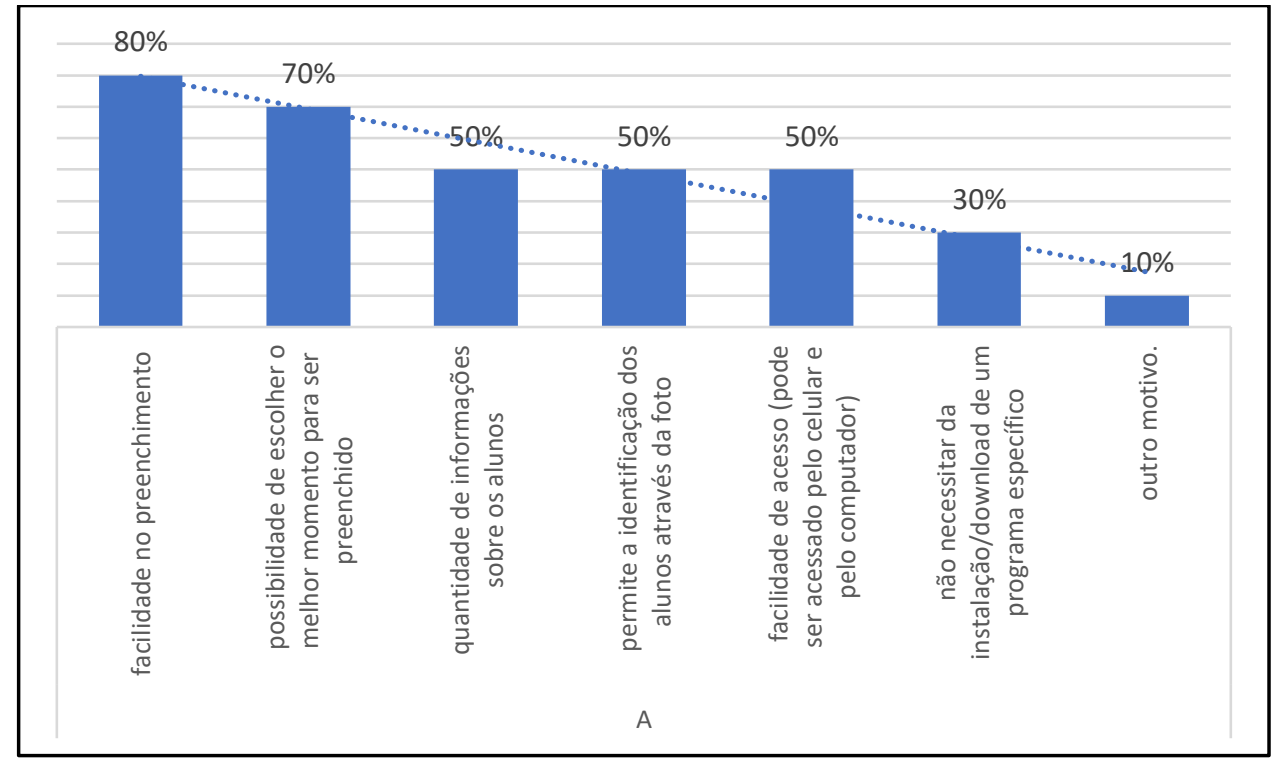

Fonte: As autoras, com base nas respostas aos questionários (2019)

Não houve respostas dos docentes quanto à sugestão de outras características do software que tivesse chamado atenção dos professores, além das anteriormente apontadas.

Quanto ao melhor momento de utilização do software (Pré-conselho, Conselho de classe em si, Pós-conselho ou todos os anteriores), 80\% dos professores respondeu que o software pode ser manuseado para a realização em todos os momentos do processo avaliativo e 20\% dos respondentes consideram que o melhor momento para utilizar esse apoio tecnológico seria o pré-conselho, como forma de levantamento de dados prévios da condição de aprendizagem dos alunos.

Sobre o que os professores usuários do software julgaram que seria necessário modificar ou aperfeiçoar no sistema, das 10 respostas, nenhuma delas sugeriu modificações.

No entanto, houve duas observações relevantes: a primeira, em relação ao uso das informações, que, na opinião do(a) professor(a) respondente, as informações obtidas através do software acabam por se repetir no Conselho de Classe presencial; a segunda (que se caracteriza mais como uma solicitação, visto que o pedido já consta nos dados gerados pelo software), é de que poderiam aparecer para os professores as avaliações dos alunos, em todas as disciplinas, "mostrando assim se o aluno tem dificuldades em todas as matérias ou a metodologia aplicada pelo professor deve ser revista”. É importante destacar que a referida informação é disponibilizada apenas para o pedagogo. 
Por fim, a última questão referia-se à contribuição do uso do software para a prática pedagógica dos professores. As respostas dos professores variaram apontando as seguintes contribuições:

a) à reavaliação dos alunos e das avaliações realizadas, assim como à análise de resultados para atender ou corrigir o atendimento individual aos alunos com dificuldades, conforme revelam os excertos:

P1: Os resultados permitem reavaliar algumas opiniões e posições sobre alguns alunos.

P6: É importante a avaliação individual do aluno nos apontamentos apresentados neste software.

P7: Facilitou pela leitura visual do educando, assim o professor identifica quem é o aluno e qual medida pedagógica a ser construída.

b) à reflexão coletiva sobre a condução do processo de avaliação da aprendizagem pelo professor

P3: A questão de modelo de avaliação, qual a melhor maneira de aplicar de acordo com as dificuldades dos alunos.

P9: Foi muito bom, descobri que tinha os mesmos problemas de outros colegas.

) à análise dos resultados dos alunos propiciada pelos relatórios do software tanto para professores como a equipe escolar

P10: A medida em que facilitou a visualização do rendimento e das necessidades dos alunos não somente para o professor, mas para toda a equipe escolar.

P5: Nas escolhas das atividades e na análise dos resultados.

d) à definição de ações no interior da escola com base nas informações organizadas no software

P 10: Com as informações objetivas disponíveis é possível implementar práticas mais eficazes e pontuais.

P8: Levantamento de pontos críticos que deverá se dar atenção e correção.

A análise dos resultados possibilita afirmar que utilizar o software nos diferentes momentos do Conselho de Classe pode contribuir para a discussão e interpretação da aprendizagem e desenvolvimento dos alunos com uma participação mais ativa dos professores na avaliação do processo de aprendizagem desencadeado nas escolas. Os docentes que integraram a pesquisa reconhecem que o software possibilita uma gama de informações importantes sobre os alunos, identificando quais são suas dificuldades, tanto de forma individual quanto coletiva, quando analisados os resultados nas diferentes disciplinas do currículo escolar. 
Entretanto, não foi possível observar respostas que sugerissem uma reflexão sobre a própria prática docente. Neste sentido, Dalben (2004, p. 64) afirma que:

O paradigma pedagógico preponderante é aquele em que existe uma relação dicotômica professor $\mathrm{x}$ aluno, em que existe um ser que dever ser educado e outro que deve educar, em que existe um elemento para ser avaliado em seu desenvolvimento e outro que deve desenvolver esse processo numa perspectiva unidirecional.

Podemos inferir isso quando vemos que entre os respondentes, apenas um deles citou que os dados gerados pelo software podem mostrar a necessidade de se repensar a metodologia do professor para que os alunos aprendam efetivamente; ou ainda, quando outro(a) professor(a) sugere a escolha das atividades ou a melhor maneira de aplicar a avaliação para os alunos com dificuldades, a partir da análise dos dados obtidos pelo software. Ou seja, ainda é a minoria que entende que a avaliação dos alunos está diretamente relacionada à prática do professor, a qual também precisa ser avaliada.

Atualmente, é fato incontestável o avanço das tecnologias de informação e comunicação no contexto social e, consequentemente, no educacional. Desburocratizar a realização dos conselhos de classe nas escolas pode ser um dos caminhos para criar espaços de avaliação coletiva em uma perspectiva formativa que propiciem a tomada de decisões qualitativas voltadas para a melhoria dos processos de ensino e aprendizagem. Acredita-se que o software Conselho de Classe On-line pode contribuir nesse sentido.

\section{Considerações finais}

O presente artigo objetivou apresentar uma experiência coletiva utilizando-se de um software, para a realização do Conselho de Classe numa escola de Ensino Fundamental.

A partir da prática desenvolvida e dos depoimentos dos(as) professores (das), foi possível elencar alguns pontos importantes: a) que os relatórios gerados pelo software propiciam o conhecimento de informações importantes para professores e equipe escolar, sendo um apoio tecnológico significativo; b) que a avaliação dos alunos e do próprio processo avaliativo devem ser realizadas e revisadas periodicamente, num contínuo movimento de açãoreflexão-ação; c) que a experiência e a reflexão coletivas são importantes na superação de dificuldades comuns; e d) que as análises desencadeadas pelo conhecimento de dados podem desenvolver ações pedagógicas específicas para a superação das dificuldades de aprendizagem dos alunos.

No que se refere à utilização do software, pode-se afirmar que o mesmo permitiu aos professores facilidade no acesso e ganho de tempo nos registros, principalmente quando se retomam os padrões mais comuns de realização dos Conselhos de Classe, que tradicionalmente acarretam muitas tarefas burocráticas para as equipes pedagógicas e professores. Além disso, possibilitou à equipe escolar um olhar mais objetivo e pragmático sobre o desempenho escolar dos alunos, e quais ações devem ser tomadas para a superação das dificuldades apresentadas. 
É possível afirmar, com base nos depoimentos, que apenas as informações geradas pelo software, por si só, não interferem significativamente no trabalho docente; o que dá sentido aos dados é a compreensão dos mesmos, alicerçados numa análise profunda feita pelo professor sobre a sua própria prática e a realidade dos alunos. Quando o professor percebe que a avaliação da/para aprendizagem do aluno se estabelece numa relação de interdependência com o seu trabalho pedagógico, inicia-se uma "práxis pedagógica", ou seja, o movimento de agir, avaliar, reavaliar e, se for necessário, transformar suas ações.

O uso do software Conselho de Classe on-line ainda possibilitou à equipe escolar uma experiência de análise de contextos diferentes, no entanto, complementares; num primeiro momento, o professor individualmente avalia seus alunos em sua disciplina; num outro momento, numa prática coletiva, compartilha opiniões, reflexões e percebe que muitas vezes não está sozinho em uma dificuldade; dessa forma, o momento coletivo lhe permite pensar e repensar suas ações, e superar dificuldades comuns.

Por fim, o software "Conselho de Classe on-line" configura-se como um apoio tecnológico significativo para desencadear ações pedagógicas pontuais na aprendizagem dos alunos e na superação de dificuldades comuns, e pode contribuir sobremaneira na inovação dos processos avaliativos no interior das escolas, aliando tecnologia, reflexão e ações pedagógicas.

\section{Referências}

BRASIL. Decreto no 63.914 de 26 de dezembro de 1968. Provê sobre o Programa de Expansão e Melhoria do Ensino Médio (PREMEM) e dá outras providências. Disponível em: < https://www2.camara.leg.br/legin/fed/decret/1960-1969/decreto63914-26-dezembro-1968-405261-publicacaooriginal-1-pe.html>. Acesso em 31 out. 2019.

BRASIL. Lei no 5692 de 11 de agosto de 1971. Fixa Diretrizes e Bases para o ensino de $1^{\circ}$ e $2^{\mathrm{O}}$ graus, e dá outras providências. Disponível em: <https://www2.camara.leg.br/legin/fed/lei/1970-1979/lei-5692-11-agosto-1971357752-publicacaooriginal-1-pl.html>. Acesso em: 31 out. 2019.

BONFIM, José Gilberto Nunes. Informatização da gestão pedagógica na escola: uma proposta para o diálogo. In: PARANÁ. Secretaria de Estado da Educação. Superintendência de Educação. In: Os desafios da escola pública paranaense na perspectiva do professor PDE - Produções Didático-Pedagógicas,2014. Disponível em: <http://www.diaadiaeducacao.pr.gov.br/portals/cadernospde/pdebusca/producoes _pde/2014/2014_unicentro_ped_pdp_jose_gilberto_nunes_bonfim.pdf > . Acesso em: 15 ago.2019. 
DALBEN, Ângela Imaculada Loureiro de Freitas. Conselhos de classe e avaliação: perspectivas na gestão pedagógica da escola. Papirus Editora, 2004.

DALBEN, Ângela Imaculada Loureiro de Freitas. Conselho de classe. In: OLIVEIRA, D.A.; DUARTE, A.M.C.; VIEIRA, L.M.F. DICIONÁRIO: trabalho, profissão e condição docente. Belo Horizonte: UFMG/Faculdade de Educação, 2010. CDROM.

FERNANDES, Domingos. Para um enquadramento teórico da avaliação formativa e da avaliação sumativa das aprendizagens escolares. In: ORTIGÃO, Maria Isabel Ramalho et. al. (org.). Avaliar para aprender no Brasil e em Portugal: perspectivas teóricas, práticas e de desenvolvimento. p.139-163, Curitiba : CRV, 2019.

FRANCO, Maria Amélia do Rosário Santoro. Prática pedagógica e docência: um olhar a partir da epistemologia do conceito. Revista Brasileira de Estudos Pedagógicos, Brasília ， v. 97, n. 247, p.534-551.2016. Disponível em: $<$ http://www.scielo.br/scielo.php?script=sci_arttext\&pid=S217666812016000300534\&lng=en\&nrm=iso >. Acesso em: 30 out. 2019.

HADJI, C. Avaliação desmistificada. Porto Alegre: Artmed, 2001.

LOPES, José; SILVA, Helena Santos. 50 técnicas de avaliação formativa. Lisboa: Lidel, 2012.

PARANÁ. Secretaria de Estado da Educação. Caderno de apoio para elaboração do regimento escolar. Curitiba, 2007. Disponível em: $<$ http://www.diaadiaeducacao.pr.gov. br/diaadia/diadia/arquivos/File/escola/Regimento\%2oEscolar.pdf>. Acesso em: 30 set. 2019.

PARANÁ. Conselho Estadual de Educação. Instrução no 15/2007 - SUED/SEED. Avaliação do Aproveitamento Escolar, Recuperação de Estudos e Promoção dos(as) estudantes das instituições de ensino da rede pública estadual de ensino do Estado do Paraná, exceto para modalidade da Educação de Jovens e Adultos (EJA). Curitiba, 2007.

Disponível

em: <http://www.educacao.pr.gov.br/arquivos/File/instrucoes2017/instruca0152017_s ued_seed.pdf $>$. Acesso em: 30 set. 2019.

PARANÁ. Dia a dia educação. Instâncias colegiadas. Disponível em: < http://www.gestaoescolar.diaadia.pr.gov.br/modules/conteudo/conteudo.php?cont eudo=60>. Acesso em: 15 set. 2019.

PARANÁ. Secretaria de Estado da Educação. Caderno de apoio para elaboração do regimento escolar. Curitiba, 2007. Disponível em: $<$ http://www.diaadiaeducacao.pr.gov. br/diaadia/diadia/arquivos/File/escola/Regimento\%20Escolar.pdf $>$. Acesso em: 30 set. 2019. 
PERRENOUD, Philippe. Avaliação: da excelência à regulação das aprendizagens- entre duas lógicas. Tradução Patrícia Chittoni Ramos. Porto Alegre: Artes Médicas Sul, 2008.

SILVA, Giane Correia; SILVA, Viridiana Alves Lara. Avaliação da/para aprendizagem. In: BRANDALISE, Mary Ângela Teixeira; SILVA, Giane Correia (org.). Avaliação Educacional: revisitando conceitos e perspectivas. Ponta Grossa: UEPG, 2019. No prelo.

TARAS, M. Assessment: summative and formative: some theoretical reflections. British Journal of Educational Studies, v. 53, n. 4, p. 466-478, nov. 2005.

\section{Biografia Resumida}

Michélle Barreto Justus - Licenciada em Pedagogia pela Universidade Estadual de Ponta Grossa (UEPG), Mestre em Educação pela UEPG. É professora pedagoga da rede pública estadual de ensino e professora colaboradora do Departamento de Educação da Universidade Estadual de Ponta Grossa (DEED/UEPG). Integrante do Grupo de Pesquisa em Política Educacional e Avaliação (GEPPEA) da UEPG.

Lattes: http://lattes.cnpq.br/3514793033783185

Contato: pedagogamichelle@yahoo.com.br

Mary Ângela Teixeira Brandalise - Licenciada em Matemática pela Universidade Estadual de Ponta Grossa (UEPG), Mestre em Educação pela UEPG, Doutora em Educação pela Pontifícia Universidade Católica de São Paulo (PUC/SP). É professora sênior do Programa de Pós-Graduação em Educação e do Programa de Ensino de Ciências e Educação Matemática da (UEPG). É coordenadora do Grupo de Estudos e Pesquisas em Política Educacional e Avaliação (GEPPEA). Membro do Grupo de Estudos e Pesquisas em Políticas de Avaliação e Accountability na América Latina da Universidade do Oeste de Santa Catarina (UNOESC). Membro da Rede Universitas/Br. Membro da Red de Estudios Teóricos y Epistemológicos en Política Educativa (RELEPE).

Lattes: http://lattes.cnpq.br/3215978829755641

Contato: marybrandalise@uol.com.br 